\title{
GÊNERO E O TRABALHO NA PECUÁRIA FAMILIAR: UMA LEITURA A PARTIR DA DIVISÃO SEXUAL DO TRABALHO ${ }^{1}$
}

\author{
GENDER AND WORK IN FAMILY LIVESTOCK: \\ A READING FROM THE SEXUAL DIVISION OF LABOR
}

Tatielle Belem Langbecker ${ }^{2}$

RESUMO: Este artigo tem por objetivo analisar elementos da estrutura de trabalho e das dinâmicas familiares que identifiquem a divisão sexual do trabalho na pecuária familiar em Encruzilhada do Sul/RS, calcadas na perspectiva de gênero. Sinaliza-se que a situação das mulheres na pecuária familiar em determinada realidade no Rio Grande do Sul concorda com a ótica da divisão sexual do trabalho na agricultura, constituída pelas atividades de trabalho determinadas conforme os sexos. Metodologicamente fundamenta-se na perspectiva qualitativa utilizando-se de entrevistas com mulheres pecuaristas familiares e analisando-as a partir da análise de conteúdo categorial. Por fim, salienta-se que a pecuária de corte local carrega aspectos socioculturais que a instituem como atividade masculina. As mulheres são responsabilizadas por trabalhos "auxiliares", mesmo que sejam os mesmos desempenhados pelos homens.

Palavras-chave: Divisão de sexual do trabalho, gênero, pecuária familiar.

ABSTRACT: This article aims to analyze elements of work structure and family dynamics that identify the sexual division of labor in family livestock in Encruzilhada do Sul / RS, based on gender perspective. It is pointed out that the situation of women in family livestock in a certain reality in Rio Grande do Sul agrees with the view of the sexual division of labor in agriculture, constituted by work activities determined according to the sexes. Methodologically, it is based on a qualitative perspective, using interviews with women family farmers and analyzing them from the categorical content analysis. Finally, it should be pointed out that the local cattle-raising has socio-cultural aspects that establish it as a male activity. Women are held responsible for "auxiliary" work, even if it is the same as that performed by men.

Keywords: Division of sexual work, genre, family livestock.

\section{INTRODUÇÃO}

As atividades ditas femininas, analisadas a partir da divisão sexual do trabalho na agricultura, são definidas como ajuda à estrutura familiar, ainda que o trabalho desenvolvido seja equivalente ao masculino ou o mesmo praticado pelos homens. Por conseguinte, desmotivadas em permanecer no campo, em função das desigualdades vivenciadas no ambiente familiar da agricultura, uma parcela considerável de mulheres inseridas na atividade, geralmente mais jovens, optam pela migração às cidades, já que no rural são poucas as perspectivas profissionais. Isto contribuiu, ao longo do tempo,

\footnotetext{
${ }^{1}$ Este artigo foi extraído da dissertação de mestrado em Desenvolvimento Rural/UFRGS.

${ }^{2}$ Doutoranda em Extensão Rural, Universidade Federal de Santa Maria, tatielle.belem@gmail.com.
} 
para a invisibilidade socioeconômica da mulher atuante no rural, especialmente, aquelas que estão inseridas em atividades rurais de cunho familiar (BRUMER, 2004).

Pensando a multifuncionalidade do rural, as possibilidades de diferentes configurações de produção e trabalho são inúmeras. A agricultura familiar é uma das formas encontradas de agricultura no país, a qual apresenta algumas características pontuais que caracterizam as atividades familiares como, a utilização predominante de mão de obra familiar, detenção de áreas não maiores que quatro módulos fiscais, fonte de renda advinda de atividades econômicas associadas ao próprio estabelecimento e direção do estabelecimento ou empreendimento familiar (BRASIL, 2006).

Com base nisso, direciona-se estas reflexões à determinado tipo de dinâmica familiar, ou, aos "[...] agricultores familiares que criam bovinos de corte", denominados como pecuaristas familiares por Ribeiro (2009, p. 63). De acordo com o autor, a terminologia refere-se aos produtores que apresentam características semelhantes aos agricultores familiares, como pequenas áreas, porém desenvolvem a bovinocultura de corte extensiva associadas, em sua maioria, a outras atividades.

A situação das mulheres na pecuária familiar, frequentemente, é desvalorizada e não reconhecida. Responsabilizam-se pelo trabalho com a casa e filhos, em maioria, sem remuneração, o que desconsidera suas contribuições para o desenvolvimento conjunto da família. A realidade das mulheres inseridas na pecuária de corte familiar é pouco discutida, já que a atividade apresenta características culturais que a "instituem" como masculina. Em parte, essa configuração decorre da influência histórica e sociocultural da Metade Sul do Rio Grande do Sul ao remeter à bovinocultura de corte. A região, por vezes, é reconhecida como detentora de médias a grandes produções e propriedades, entretanto a realidade vivenciada por muitas famílias é desconhecida, pois as atividades familiares são ocultadas nesse contexto de produção e trabalho (RIBAS; SEVERO; MIGUEL, 2004).

Melo e Di Sabbato (2009, p.34) apresentam discussões de gênero encontradas no rural, buscando emergir maneiras mais consistentes de avaliar as diferentes situações de mulheres e homens na sociedade, sendo necessária, a ampliação da visão sobre os "papeis" estabelecidos pela cultura e pela própria sociedade. No sentido de compreender as situações/condições de trabalho de mulheres inseridas nas atividades da pecuária familiar, a partir da perspectiva de gênero, em um contexto reconhecido como masculino, justifica-se a intenção deste artigo em analisar elementos da estrutura de trabalho e das dinâmicas familiares que identifiquem a divisão sexual do trabalho na pecuária familiar em Encruzilhada do Sul/RS.

Assim, apresentar perspectivas e situações de mulheres nas atividades rurais induz à reflexão de que o ambiente não deve ser analisado apenas a partir de uma visão homogênea e, sim considerar a "[...] situação de convivência entre indivíduos de sexos diferentes, que realizam atividades produtivas e, compartilham um projeto de sobrevivência" (SOUZA; SILVA, 2012, p. 2012). Partindo 
desse raciocínio destaca-se que as análises aqui apresentadas foram extraídas de um trabalho de dissertação.

\section{O RURAL E AS ASSIMETRIAS DE PODER: O GÊNERO COMO ELEMENTO EXPLICATIVO DE SITUAÇÕES/CONDIÇÕES VIVENCIADAS POR MULHERES RURAIS}

A definição de gênero proposta por Joan Scott (1995, p. 21-23) se refere à construção social das relações sociais fundamentadas nas diferenças entre os sexos. A definição compõe-se de duas partes e várias subpartes, isto é, uma das partes representa essa construção baseada em diferenças biologicamente percebidas, e a outra fundamentada na relação de gênero como forma primordial das relações de poder. Há ainda outros quatro elementos constitutivos das relações sociais: simbologia cultural, conceitos atrelados aos símbolos que denotam interpretações, permanência da dualidade representativa dos gêneros e a identidade subjetiva dos sujeitos.

A relação das duas partes trazidas por Scott (1995) denota nitidamente a dependência de uma a outra, ou seja, o poder presente nas relações de gênero fundamenta-se nas diferenças percebidas biologicamente. Isso implica a compreensão de que as estruturas hierárquicas se baseiam em relações "naturalmente" estabelecidas entre homens e mulheres.

O gênero como categoria analítica revela-se com potencial para explorar as relações de desigualdades inseridas no rural e, especificamente, na pecuária. No rural, as assimetrias de gênero são evidentes, pois, como diz Brumer (2004), culturalmente, a mulher é destinada a desempenhar determinadas atividades produtivas e reprodutivas e a conformar-se com a tradicional distribuição de poder e de acesso à terra, permanecendo em uma posição subordinada no ambiente familiar.

A noção de "ajuda" instituída ao trabalho feminino predomina fortemente em contextos em que há a presença da agricultura familiar. Contudo, o questionamento dessa ideia do trabalho da mulher rural representado pela noção de "ajuda", colabora para o reconhecimento feminino diante das práticas socioeconômicas cotidianas presentes nas dinâmicas das famílias rurais. Com base em Scott (2010, p. 24), isso permitiria visualizar as relações de poder imersas em um processo de contínua negociação entre homens e mulheres em diferentes domínios de poder. No entanto, é possível afirmar-se que as formas simbólicas de dominação, persistentes historicamente, são ainda eficientes em submeter e relegar o trabalho feminino ao desvalor expresso na definição de "ajuda".

\section{A DIVISÃo SEXUAL DO TRABALHO: CENÁRIO DE PERMANÊNCIAS}


As relações sociais de sexo (nos estudos franceses) apontam uma ruptura com as explicações que consideram as características biológicas como determinantes das práticas sociais, e afirmam que as diferenças entre sexos estão fundadas na construção social, na hierarquia e poder estabelecidos entre os sexos, o que permitiria uma construção histórica. (KERGOAT, 1996).

Classicamente, a separação entre as atividades femininas e masculinas, explícitas na divisão sexual do trabalho, estabelece aos homens a inserção na esfera produtiva, vinculando-os às ações de maior valor social, e as mulheres ficam imersas nas atividades de cunho reprodutivo correspondendo aos dois princípios básicos da divisão sexual do trabalho: separação e hierarquização dos trabalhos de homens e mulheres (HIRATA; KERGOAT, 2007).

As autoras afirmam que os "critérios" que desenham a divisão sexual do trabalho são reconhecidos e naturalizados pelos aspectos biológicos em todas as sociedades. Entretanto, isso não significa que a definição seja imutável; ao contrário, apresenta inúmeras variações conforme o contexto histórico, geográfico e as inter-relações entre as diferentes formas de divisão social de trabalho (HIRATA; KERGOAT, 2007, p. 599-600).

Ao tratar da divisão sexual do trabalho, enfatiza-se a importância de conceituar trabalho e de associá-lo à divisão sexual do saber e do poder. A definição de trabalho, nesta perspectiva, “[...] é um conceito ampliado, que inclui o trabalho profissional e doméstico, formal e informal, remunerado e não remunerado" (HIRATA, 2010, p. 1). Já as relações sexuais de saber e poder referem-se às atribuições dadas às mulheres e aos homens, isto é, as responsabilidades direcionadas às mulheres pela educação dos filhos, condicionam-nas a ocupar posições inferiores aos homens no mercado de trabalho.

Ao encontrar possibilidades que permitam a reflexão para além do naturalismo institucionalizado entre as diferenças de sexo no trabalho, essas se constituem em razão e consequência de questionamentos acerca das constantes desigualdades entre homens e mulheres, ou ainda, da hierarquia calcada entre os sexos. Entretanto o dualismo entre trabalhos produtivos (masculino) e reprodutivos (feminino) permanece ainda atual, definindo os modelos de trabalhadores. Esse dualismo se sustenta, em parte, na ideia das qualidades naturais femininas em desempenhar determinadas atividades, como por exemplo, cuidados de saúde (LOPES, 1996, p. 57-59). Essas ideias, de fato, submetem-se a novos marcos históricos, mas, estudos atuais da autora apontam permanências que se sustentam onde convém ao sistema capitalista.

Postas algumas contribuições sobre a divisão sexual do trabalho, remete-se a Kergoat (2010) no intuito de sintetizar reflexões. É importante articular a fundamentação da divisão sexual do trabalho com as relações sociais de sexo, pois a primeira refere-se às situações empíricas e a segunda fornece o suporte teórico. As práticas sociais, por exemplo, a divisão sexual do trabalho, compõem 
modalidades nas diferentes relações sociais, especificamente aqui, referindo-se às relações sociais de sexo.

Nessas bases, as noções e reflexões acima, articuladas na problemática empírica, "trabalho feminino na pecuária", resultaram em novos questionamentos ou no aprofundamento de olhares investigativos sobre o tema. Este artigo traz esse esforço reflexivo.

\section{CAMINHOS METODOLÓGICOS}

A abordagem qualitativa foi a escolhida, pois este tipo de abordagem empenha-se em apresentar e compreender a complexidade do contexto estudado. Definiu-se a situação das mulheres nas atividades de trabalho na pecuária familiar como objeto de pesquisa e posteriormente delimitouse o método. Esta pesquisa delineou-se como estudo de caso, pois permite explorar situações não delimitadas da vida real, descrever o contexto do ambiente onde se realiza a pesquisa e explicar as variáveis que desencadeiam fenômenos específicos (GIL, 2008).

A opção pelo município de Encruzilhada de Sul, como ambiente empírico, se deu de forma intencional por representar situação emblemática inserida na Metade Sul do Rio Grande do Sul. O município apresenta grande área territorial com aproximadamente $3.348,319 \mathrm{Km}^{2}$, uma população estimada em 2015 de 25.726 de habitantes, respondendo em uma densidade populacional de 7,33 habitantes por $\mathrm{Km}^{2}$ (IBGE, 2016), localizando-se ao sul do Rio Grande do Sul, especificamente, na Mesorregião do Sudeste Rio-grandense e Microrregião da Serra do Sudeste (FEEDADOS, 2016).

Essa região é reconhecida por apresentar condições socioeconômicas que respondem em baixa dinamicidade produtiva, ao comparar com outras regiões do estado, assim como, desigualdades de renda que resultam em situações extremas vivenciadas pela sociedade ali inserida, especialmente, referindo-se ao rural (RIBAS; SEVERO; MIGUEL, 2004).

Para a identificação e definição das participantes da pesquisa, realizada de forma intencional, contou-se com o auxílio do serviço de extensão rural (EMATER) de Encruzilhada do Sul, em virtude do contato direto com as famílias rurais e conhecimento das realidades específicas. Com isso, confirmou-se a participação feminina na pecuária familiar, possibilitando, ainda, o acesso a essas mulheres, tornando a pesquisa viável. Os primeiros contatos com as entrevistadas, o pré-campo e as duas entrevistas piloto, foram realizados em conjunto com técnicos da Emater, possibilitando estabelecer relação de confiança e tranquilidade às participantes. As entrevistas-piloto foram inclusas na totalidade do material para análise devido à qualidade do material. Além dessas, realizaram-se outras treze entrevistas em julho de 2015, totalizando 15 entrevistas válidas para análise. 
Através da saturação dos dados se identificou o número de entrevistadas, ou o "limite" de participantes, isto é, “[...] quando as concepções, explicações e sentidos atribuídos pelos sujeitos começam a ter uma regularidade de apresentação" (DESLANDES, 2007, p. 48). A geração de dados se deu por entrevistas semiestruturadas junto às participantes, possibilitando ao entrevistado expor suas ideias com a liberdade de expandir suas respostas além dos questionamentos (MINAYO, 2007).

A organização e interpretação das informações geradas foi realizada por meio da análise de conteúdo temática. Resumidamente, desenvolveram-se as três principais etapas realizadas para se obter uma análise de conteúdo: leitura flutuante, seleção das unidades de análise e categorização (CAMPOS, 2004, p. 613). A análise temática foi definida como primeira escolha por apoiar-se em identificar a composição da comunicação através de "núcleos de sentido" cuja frequência e presença expressam significados para o objeto em análise (CAMPOS, 2004, p. 612-613). A categorização foi realizada utilizando o software NVivo 8 como ferramenta de apoio que, conforme Guizzo, Krziminski e Oliveira (2003, p. 56), auxilia na organização e análise dos dados.

\section{OCUPAÇÕES E AUTO IDENTIFICAÇÃO: NUANCES DA DIVISÃO SEXUAL DO TRABALHO NA PECUÁRIA FAMILIAR}

No livro Mulheres na Guerra dos Farrapos destaca-se um trecho cuja divisão sexual do trabalho fica explícita, suscitando reflexões sobre as persistências e rupturas de um contexto permeado de subalternidades e hierarquizações no que tange ao trabalho feminino:

\footnotetext{
Cabe lembrar que no Rio Grande do Sul, em séculos pretéritos o homem dominava o espaço "de fora", comércio, expansionismo, guerras, devendo a mulher permanecer no espaço doméstico. A tarefa coordenada pelo Arsenal atendia a esse importante quesito. Costura era atividade executada no lar, que permitia à mulher controlar o governo da casa e o trato dos filhos (FLORES, 2013, p.29).
}

A citação remonta à primeira metade do século XIX, em meio a Guerra dos Farrapos, e ao apelo a mão de obra feminina para a confecção de 12 mil uniformes para homens combatentes (FLORES, 2013). A autora refere que, em tempos passados, os homens eram responsáveis pelas atividades de cunho público e produtivo, enquanto as mulheres permaneciam controlando as atividades domésticas e a criação dos filhos. Nesse sentido, a análise subsequente busca compreender a situação de mulheres nas atividades de trabalho na pecuária familiar, em grande medida originada das estâncias sesmeiras, e analisar mudanças e permanências na divisão de atividades e espaços.

A perspectiva adotada desnaturaliza o trabalho realizado por homens e mulheres considerando-o como produtos da construção social assentada nas desigualdades de gênero. O argumento que define características femininas e masculinas como "naturais" no desenvolvimento de 
diferentes atividades na sociedade dissolve-se no tempo e no espaço, pois como analisa Lopes (1996, p.58), “[...] uma tarefa especificamente masculina em uma sociedade pode ser especificamente feminina em outra".

No entanto, a tradicional naturalização das atividades de trabalho com base no sexo ou, na cultura dominante de gênero, está expressa na fala de algumas entrevistadas, ao serem questionadas sobre sua ocupação/profissão na propriedade familiar:

Eu aqui, eu sou homem e eu sou mulher, tudo... os dois sabe, eu tanto atendo a minha lida como atendo a lida dele, porque ele trabalha de biscate né, e aí... aí eu me vejo... Agora a guria [filha] está comigo, porque ela mora, está estudando em Santana né. Nas férias ela vem, os fins de semana ela vem, mas a maior parte do tempo é só eu e os dois guris [filhos], e os guris vão pra escola, ele [marido] sai pro serviço... Aí eu tenho que atender (Entrevistada 5).

A separação entre atividades femininas e masculinas é mencionada claramente nas expressões "eu sou homem e eu sou mulher" e "atendo a minha lida como atendo a lida dele". A execução das atividades é realizada pela entrevistada independente da relação de responsabilidades estabelecidas na dinâmica familiar e, ainda assim não há a apropriação das atividades pela mulher, permanecendo a demarcação delineadora das atividades femininas e masculinas. É como se as atividades tivessem uma titularidade, mostrando que, simbolicamente, as mulheres admitem que fazem tarefas que não são delas. Na vida prática, a propriedade cultural das atividades se dilui.

Essa persistência em manter o discurso que divide as atividades de acordo com os sexos, mesmo sendo a mulher executora de atividades consideradas masculinas, pode ser percebida como a materialização da subjetividade das relações de dominação masculina: “[...] os dominados aplicam categorias construídas do ponto de vista dos dominantes às relações de dominação, fazendo-as assim serem vistas como naturais" (BOURDIEU, 2002, p. 41).

Em relação à ocupação/profissão das entrevistadas, algumas das participantes destacaram a relação mútua entre os cuidados com a casa e com a produção como características de suas ocupações:

Ah, eu faço toda lida. Faço a lida da casa, cuido dos bichos. E se for preciso ajudar alguma coisa na lavoura, a gente ajuda. Muita coisa tem o guri [filho] que ajuda né. Aí eu fico mais na volta de casa. Cuido dos bichos e os afazeres da casa (Entrevistada 2).

A relação com o "cuidar" perpassa as barreiras das atividades realizadas dentro de casa e ganha espaço com o trabalho desenvolvido na produção, especialmente quando se trata dos cuidados com os animais. O trabalho na lavoura passa a ser entendido como "ajuda". A lida com a criação e com os afazeres domésticos como cuidados, ou seja, o trabalho desempenhado pelas mulheres não é definido como tal, acentuando o entendimento de que o cuidado caracterizar-se-ia como elemento inerente ao feminino. Isso decorre dos pressupostos intrínsecos à socialização das meninas atribuindo 
às mulheres o cuidado dos filhos, familiares e assim incorporando a tarefa de guardar a família mantendo as tradições (TEDESCHI, 2004, p. 49).

Apesar das atividades produtivas investigadas corroborarem com a definição de pecuária familiar, poucas participantes atestam sua ocupação/profissão como pecuarista. Talvez pelo próprio desconhecimento da categoria social “pecuarista familiar”, já que a visão sobre a atividade, em vários momentos, é associada à pecuária de alto valor econômico. Apesar disso, encontram-se mulheres que mencionam a pecuária como sua ocupação/profissão e, igualmente, têm-na como elemento definidor de sua identidade:

Eu me identifico como pecuarista. Não vou dizer que é do lar porque eu faço as coisas de casa obrigada, porque se eu pudesse anoitecer e amanhecer no campo, eu anoitecia e amanhecia (Entrevistada 4).

A entrevistada refere-se à pecuária como sua identidade profissional e, além disso faz perceber sua insatisfação em realizar os trabalhos domésticos (obrigação de mulher, não escolha), reafirmando sua preferência em desenvolver as atividades de campo. Duas das participantes caracterizam-se como pecuaristas, dentre as quais cada membro do casal possui uma parcela de terra devido à herança; nos demais casos isso não é constatado: ou a terra está no nome da mulher ou no nome do homem. As chances dessa titularidade contribuir na explicação das atribuições sobre a identificação e ocupação/profissão das participantes são consideráveis, pois a herança familiar é apontada por Cotrim (2003) como um dos elementos contributivos na formação do pecuarista familiar.

Desta forma, observa-se uma ruptura do padrão social e histórico que delimita o homem apenas como se autodenominando o pecuarista, o responsável pela lida com o gado (RAUBER, 2010, p. 50). Observa-se que, além da propriedade da terra mesclar-se entre o homem e a mulher, algumas mulheres também se autodenominam pecuaristas. Provavelmente esse fato indique tradição familiar em exercer a pecuária ou o sentido restrito de posse de animais.

Ainda há casos em que as entrevistadas afirmam a agricultura como ocupação/profissão, motivadas em virtude da denominação adotada no bloco de notas de produtor rural, chamado pelas participantes de livro ou livro de produtor:

A nossa profissão? Nos livros da gente, a gente é agricultora né. Eu trabalho aqui na escola, mas aí comprova que eu trabalho, porque aqui eu não tenho carteira assinada. Aí a gente é agricultora (Entrevistada 9).

Minha profissão? Eu já te digo já. Eu sou pequeno agricultor. Faço todas as lidas, mas a minha principal atividade é essa. Tenho o meu livro de produtor, como eu te disse né, e funciona com ele (Entrevistada 10). 
A comprovação de trabalho perante a Previdência Social é realizada por meio do bloco de notas, como se observa na fala da entrevistada nove, pois os serviços realizados pela participante na escola da comunidade onde reside apresentam caráter informal. Em primeira instância, a impressão que se tem é que a ocupação/profissão agricultora é consequência da denominação que consta no bloco de notas e não uma afirmação de identidade. Porém, na segunda situação, a referência ao "livro de produtor" parece carregar maior importância na perspectiva da denominação. Essas diferentes situações são explicadas por Brumer (2004, p. 223), quando a autora constata que a inserção do nome da mulher no bloco de notas demonstra valores materiais e simbólicos. O primeiro relaciona-se à possibilidade de comprovação de seu trabalho para o gozo dos benefícios da Previdência Social e o segundo torna visível a profissão de agricultora contribuindo na visibilidade de seu trabalho.

A autora menciona a inclusão do nome da trabalhadora rural no bloco de notas do marido, porém a realidade observada aponta a posse direta por parte das entrevistadas dos blocos de nota. Isso contribui no reconhecimento da mulher como trabalhadora rural, mas não muda a situação do trabalho subalternizado, pois a conquista dos direitos legais pelas trabalhadoras rurais, como o acesso aos benefícios sociais, não responde de forma positiva às assimetrias de gênero vivenciadas no rural. As responsabilizações materiais e simbólicas em âmbito familiar e doméstico permanecem femininas, atuando como "[...] mecanismo de contenção para o acesso das mulheres à vida pública (TEDESCHI, 2004, p.60).

Ao tratar da autoidentificação das entrevistadas, a condição que refere o bloco de notas como definidor da identidade da mulher rural se repete, isto é, garante o acesso aos benefícios sociais, mas parece representar fragilidade no que se refere à identidade. Isto pode ser verificado na fala de entrevistadas, ao serem questionadas sobre como se identificariam:

Rural. É, e até tem que ser mesmo, agricultora rural né. Por causa que é... que tem que ter depois se eu chegar a me aposentar. É rural e agricultora... Acho que agricultora está mais certo. Até porque a gente tem o livro de guia, no livro de guia é pra rural né. É pra produtor, essa é a minha profissão. Antigamente, uma mulher assim de fora que ficava só em casa era "do lar". E agora não é mais né. Essas coisas mudam muito (Entrevistada 2).

O valor simbólico de ter um bloco de notas com o seu nome, observado por Brumer (2004), é de fundamental importância para essas mulheres, pois lhes oferece uma identidade de trabalhadora rural, de agricultora, que nem mesmo elas tinham ciência da possibilidade. A entrevistada remete à anterior identificação das mulheres inseridas no rural como "do lar", ou seja, conotação explícita limitando as mulheres exclusivamente às práticas domésticas, sem considerar o trabalho desenvolvido na esfera produtiva. As representações sociais sobre os binômios casa/campo e mulher/homem, assim como as respectivas relações, são tão fortes e incorporadas nas práticas cotidianas de trabalho, que 
além de reforçarem a hierarquização de trabalhos e produtos (TEDESCHI, 2012), colaboram para dificultar a percepção da mulher sobre sua identidade.

\section{TEMPO E TRABALHO NA PECUÁRIA FAMILIAR: COMPOSIÇÃO “ACESSÓRIA" OU PRODUTO DE UM SISTEMA DE GÊNERO DOMINANTE?}

A distribuição dos diferentes tempos entre as atividades desenvolvidas e "quem" as executa serve como importante ferramenta para a análise da divisão sexual do trabalho. Assim observa-se a insistência em basear-se em um sistema de dominação masculina consolidado em tempo e espaço, principalmente ao tratar da pecuária do Rio Grande do Sul, atividade social e historicamente construída como masculina.

A distribuição das atividades de trabalho na pecuária familiar durante o dia é relatada de maneira semelhante pelas entrevistadas. A primeira atividade desenvolvida revela os cuidados com os animais - como alimentação, revisão e controle da sanidade (aplicação de medicamentos), contagem dos animais. No turno da manhã, a maioria das mulheres retornam da lavoura a casa para realizar as tarefas cotidianas no espaço doméstico:

\footnotetext{
De manhã racionar a criação. De manhã a primeira coisa que a gente faz: levanta, toma café e vai racionar a criação. Depois, as atividades da casa... ela [nora] se tem que ir pra lavoura, vai. E ao meio dia, a gente chega, tem que fazer comida. De tardezinha de novo, racionar a criação. É sempre todos os dias, é isso aí (Entrevistada 1).
}

As realidades familiares relatadas, além de demonstrarem uma visão geral das dinâmicas de trabalho das mulheres na pecuária familiar - pecuária, atividades domésticas e lavoura (em alguns casos) -, apontam para a clássica distribuição das atividades em que, prioritariamente, os membros da família dedicam-se aos tratos com os animais na manhã e depois ocorre a distribuição entre as outras atividades, considerando o recorte de gênero e geração, como se observa no depoimento. A entrevistada afirma "não trabalho mais na lavoura", indicando que esse lugar é ocupado por mulheres mais jovens.

Essa condição é possibilitada pelo recebimento da aposentadoria, pois um dos fatores que influenciam o afastamento das mulheres mais velhas dos processos produtivos condiz com a garantia do benefício para mulheres rurais por idade, ou seja, a partir dos 55 anos. Assim, as mulheres cessam o desenvolvimento de atividades mais "pesadas" (trabalhos em lavouras, por exemplo) possibilitando-lhes maiores liberdades (BUAES, 2007, p. 108), mas ainda se responsabilizam por atividades domésticas e de criação. Isso encaminha ao entendimento de que as questões relacionadas à geração, como o envelhecimento, também são constructos sociais fundamentados na forma como determinada sociedade estabelece a existência dos indivíduos (BUAES, 2007, p. 104-105). 
Em situações em que a mulher não é aposentada, permanece a separação da atividade de lavoura (homem) e criação/casa (mulher). Isso contribui para outros olhares sobre o trabalho na lavoura e para a compreensão da força do simbólico na permanência da divisão sexual que atribui qualificativos de gênero para as atividades nesse âmbito. Isto é, as atribuições de "trabalhos leves" deveriam estar concentradas entre as mulheres e os "pesados" entre os homens (PAULILO, 2004).

Para as entrevistadas, as atividades de criação são percebidas como trabalho, pois ambas relatam permitirem-se realizar outras atividades após a lida com os animais. Contudo, o tempo livre serve para a prática das atividades consideradas como suas, ou melhor, as atividades de cunho doméstico, muitas vezes referidas como o "não trabalho". Desta forma, o trabalho doméstico não é percebido como tal, pois o tempo livre mencionado refere-se ao espaço de tempo para a realização dessas atividades, desconsiderando-as como trabalho. Isso reforça a invisibilidade e a desvalorização do trabalho feminino, resultando na "[...] dupla ou tripla jornada e na sobrecarga" de trabalho (BARBOSA, 2013, p.124).

A gente, geralmente, a gente faz junto as coisas né, dá comida pra os bichos, alimenta os bichos, depois recorre o campo, aí eu faço as lidas assim, alternadas. Eu lavo roupa, faço almoço no intervalo. Mas é assim geralmente... quando sobra um tempinho, nas horas vagas, como horário de almoço, é pra lavar uma roupa dá uma ajeitada na casa (Entrevistada 4).

Percebe-se que as mulheres desempenham as atividades do campo junto aos homens, realizando as mesmas funções de trato dos animais e lida no campo, contudo os trabalhos domésticos continuam sendo realizados pelas mulheres. Na mesma direção dos depoimentos anteriores, “as horas vagas" são utilizadas para pôr ordem na casa. Essas dinâmicas empenhadas na realização das atividades mesclam-se entre dois dos modelos de conciliação entre vida familiar e vida profissional, propostos por Hirata (2010, p. 2). Primeiramente ao modelo tradicional, onde a mulher trabalha em casa assumindo os cuidados com casa e filhos, sendo o homem o provedor, e ao modelo da conciliação, em que a mulher concilia trabalho profissional e doméstico, e o homem não. Há a intersecção entre esses dois modelos, pois a mulher continua responsabilizando-se pelos afazeres domésticos, mas também trabalha na produção, só que em ambiente de propriedade da família.

O argumento anterior reitera as múltiplas situações de trabalho encontradas na pecuária familiar, onde as mulheres estão cada vez mais envolvidas com as atividades de produção no campo e definindo as atividades domésticas como tarefas secundárias. Tanto a conciliação entre agropecuária e o doméstico quanto o desenvolvimento das atividades na agricultura, juntamente com o marido, são mais percebidas entre as mulheres mais jovens participantes da pesquisa.

Essa percepção do trabalho talvez seja motivada pela presença de outras mulheres (sogras) que permanecem dando "suporte" às tarefas domésticas. Ainda assim referem-se aos afazeres domésticos como “minhas coisas”, isto é, mesmo que haja algumas mudanças na condição feminina, 
a lógica dominante masculina conduz ao sistema de diferenciações entre o masculino e o feminino, legitimando o destino das mulheres ao espaço privado (BOURDIEU, 2002). A expressão "meu serviço”, utilizada por algumas entrevistadas, reforça as argumentações desenvolvidas.

Além disso, surge, nesse contexto, um espaço para a busca de autonomia socioeconômica da mulher, pois algumas entrevistadas comentaram sobre a prestação de serviços a terceiros, mesmo que estes serviços remontem às tradicionais atividades domésticas. A contratação informal de mulheres para a prestação de serviços relacionados ao trabalho doméstico no rural é constatada em estudo que analisou os serviços no ramo do turismo no rural. As atividades passam a ser representadas como extensão das responsabilidades realizadas em casa, aprendidas no seio materno da família sem considerar qualificações profissionais (LUNARDI, 2012, p. 100).

Essa multiplicidade de ações e a participação das mulheres no desenvolvimento de atividades não agrícolas, distantes dos ambientes tidos como masculinos, pode contribuir na promoção socioeconômica feminina intrafamiliar no que tange ao planejamento econômico e produtivo da propriedade. É importante destacar que mesmo as mulheres ingressando em atividades não agrícolas, isso não garante o direito intrafamiliar de apropriarem-se dos rendimentos rurais, mas suscita maiores possibilidades nas participações em renda e decisões (STADUTO; NASCIMENTO; SOUZA, 2013).

A prestação de serviços a terceiros apontam três situações distintas revelando elementos pontuais da estrutura e dinâmica familiar: mulheres que nunca trabalharam para terceiros; mulheres que trabalharam para terceiros antes do casamento; e mulheres que trabalham para terceiros regularmente. As últimas são minoria dentre as entrevistadas e trabalham informalmente em escola de comunidade rural e/ou prestando serviços domésticos para outras pessoas.

As mulheres que nunca trabalharam para terceiros perpassam distintas faixas etárias, condições de estado civil (casada, viúva, divorciada, união estável) e escolaridade, indicando a inexistência de parâmetros sociodemográficos que demarquem a condição de trabalho contrato, formal ou informal, das mulheres inseridas na pecuária familiar. Os delineamentos consideram caracteres da estrutura construída socialmente acerca das atribuições de gênero e de geração:

\footnotetext{
Não, nunca trabalhei, só em casa. Não, é que eu sempre fui em casa com os meus pais né. E depois eu casei, fiquei aqui, e aí foi sempre nessa lida né. Depois ficou só eu em casa, eu fiquei cuidando o pai, depois segui a minha vida, já estava... já tinha casado. Aí se terminou, aí sempre foi, a minha vida foi assim trabalhando. A lida com os bichos (Entrevistada 2).
}

As relações de trabalho expostas pelas entrevistadas recorrem a argumentos tanto de gênero como de geração. Antes do casamento essas mulheres permaneciam ocupadas com trabalhos domésticos e cuidados com os familiares, após o casamento dão seguimento a essas atividades tradicionalmente desempenhadas. Assim, pode-se falar em perpetuação da condição/situação feminina subalterna nas dinâmicas familiares rurais. Nesse sentido a socialização feminina 
empenhada no ensino-aprendizado das tarefas domésticas, com o intuito de reproduzi-las no casamento e nos cuidados com familiares, fragiliza as possibilidades de competição feminina perante o mercado de trabalho, (BRUMER, 1988, p. 1), o que de certa forma pode contribuir para a aceitação do "destino de gênero" dessas mulheres.

Situação semelhante se dá com as mulheres que trabalharam para terceiros antes do casamento e em função do mesmo decidem parar com os trabalhos realizados. Um argumento para busca de trabalhos após o casamento pode residir na condição desvalorizada no grupo familiar, e muitas vezes, também com o intuito de contribuir nas despesas familiares. Assim, algumas delas, as mais jovens partem em busca de trabalhos que auxiliem nas duas esferas: reconhecimento socioeconômico e auxílio financeiro aos familiares (WANDERLEY, 2009, p. 194).

Eu desde a idade de 11 anos que eu trabalhava em Pelotas. E ia e voltava, meus pais também moravam pra lá. Eu ajudava meus pais, naquela época tinha que ajudar, os pais da gente não tinham nada e nós somos dez irmãos. Daí eu vinha de Pelotas trazer rancho pra eles com a maior dificuldade... Depois eu casei e o meu marido já era mais caseiro, não quis saber de... (Entrevistada 10).

O casamento representa, com frequência, uma linha divisória, existe o "antes de casar" e “depois de casar" no que tange à prestação de serviços a terceiros por parte das entrevistadas, marcando também o ser jovem e o ser adulto. A finalidade da renda extra é nitidamente para obter recursos que contribuam com as despesas das respectivas famílias, porém com o casamento formamse famílias independentes (BRUMER, 2004, p. 215) quebrando a relação direta e recíproca de dependência econômica com a família biológica. Em pesquisa realizada por Brumer (2004, p. 218), a autora observa que parte dos filhos de agricultores seguiram o ofício de seus pais: os homens, principalmente, em virtude de heranças e as mulheres pelo casamento com agricultores.

Essas afirmações refletem o movimento transitório das mulheres no rural, pois em um primeiro momento, ainda na juventude, decidem trabalhar fora das propriedades rurais, em busca de autonomia ou responsabilização em auxiliar financeiramente a família. E, em um segundo momento, retornam ao campo, motivadas pelo casamento e "optam" por seguir trajetórias semelhantes às vividas por seus antecessores: agora não mais na posição de filhas e sim de esposas e mães.

Como teorizado por Bourdieu (2002, p. 55-56), o casamento atua como peça central na economia dos bens simbólicos, perpetuando o sistema masculino dominante, responsável pela legitimação das desigualdades de gênero, mesmo em tempo e espaços múltiplos perpassando as mudanças dos modos de produção econômica.

\section{CONSIDERAÇÕES FINAIS}


A expressão da divisão sexual do trabalho na clássica dicotomia trabalho de homem e trabalho de mulher é marcante nas falas das participantes. Ainda que os trabalhos desenvolvidos pelas mulheres contemplem a pecuária e a agricultura, a apropriação dos trabalhos domésticos é majoritária dentre as entrevistadas, demarcando, mais uma vez, os lugares/trabalhos de homens e mulheres. Outra relação presente no trabalho das mulheres na pecuária percebe-se quando há a inserção de lavouras no sistema produtivo familiar, pois esta passa a compor as atribuições masculinas, enquanto a criação e a casa concentram-se como responsabilidades femininas.

A divisão sexual do trabalho é nítida ao verificar os trabalhos de mulheres e homens, pois as mulheres podem "atender" tanto a sua lida (basicamente as atividades domésticas) quanto a lida “deles", dos maridos, relacionada à pecuária ou agricultura. Mesmo que as atividades construídas como masculinas sejam praticadas pelas mulheres, a titularidade da prática permanece masculina. Isso contribui para a invisibilidade e secundarização do trabalho feminino, já que as próprias mulheres não assumem as práticas do trabalho masculino como suas. Ainda, destaca-se que a permanência em definir os sexos do trabalho na pecuária familiar, pode ser compreendida como a materialização da subjetividade das relações da dominação masculina.

A distribuição das atividades de trabalho na pecuária entre os membros das famílias, entre tempos e quem executa cada trabalho, mostra-se como indicador da permanência da divisão sexual do trabalho no rural e, exemplifica como as mulheres vivenciam as práticas cotidianas a partir da perspectiva da dominação masculina. $\mathrm{O}$ trabalho das mulheres divide-se em atividades na pecuária, na lavoura (em alguns casos) e no ambiente doméstico. Em primeiro momento, são realizados os tratos com os animais e, na sequência, distribuem-se os membros da família entre as demais atividades, considerando o recorte de gênero e geração.

Também há a separação que enfatiza o recorte de gênero nos trabalhos desenvolvidos, ou seja, a separação entre lavoura (homem) e criação/casa (mulher), no intuito de estabelecer simbolicamente os pesos dos trabalhos de acordo com o sexo - leve/feminino e pesado/masculino. Esta distinção entre lavoura-homem e pecuária-mulher, pode estar associada à modernização da agricultura, pois a inserção de tecnologias na agricultura direcionou o homem a investir em maquinários e na própria qualificação técnica profissional, distanciando as mulheres deste ambiente, e, possivelmente as responsabilizando pelas atividades de criação.

O casamento representa um movimento transitório na vida das mulheres rurais, assim como, uma linha divisória entre o "antes de casar" e o "depois de casar", delineando a vida jovem e adulta das mulheres. Encerram-se os trabalhos prestados a terceiros e dá-se continuidade a realidade destinada à mulher rural, o que torna a mulher agricultora, pois uma das formas de inserção das mulheres na pecuária - e na agricultura - é justamente através do casamento. Com isso, apresentou- 
se parte da realidade do trabalho desempenhado por mulheres na pecuária familiar reforçando o entendimento que reflete a clássica dicotomia entre os sexos, especialmente, ao tratar sobre a divisão sexual do trabalho.

\section{BIBLIOGRAFIA}

BRASIL. Presidência da República. Lei $N^{o} 11.326$, de 24 de Julho de 2006. Estabelece as diretrizes para a formulação da Política Nacional da Agricultura Familiar e Empreendimentos Familiares Rurais. 2006. Disponível em: <http://www.planalto.gov.br/ccivil_03/_ato20042006/2006/lei/111326.htm>. Acesso em: 14 jun. 2016.

BRUMER, Anita. 2004. Gênero e agricultura: a situação da mulher na agricultura do Rio Grande do Sul. Revista Estudos Feministas, v. 12, n. 1. p. 205-227, jan./abril.

BOURDIEU, Pierre. 2002. A dominação masculina. Rio de Janeiro: Bertrand Brasil.

CAMPOS, Claudinei José Gomes. 2004. Método de análise de conteúdo: ferramenta para a análise de dados qualitativos no campo da saúde. Revista Brasileira de Enfermagem, v. 57, n. 5, p. 611614, set./out. 2004.

COTRIM, Marcelo Souza. 2003. Pecuária familiar" na região da "Serra do Sudeste" do Rio Grande do Sul: um estudo de caso sobre a situação socioagroeconômica do pecuarista familiar no município de Canguçu/RS. Dissertação (Mestrado em Desenvolvimento Rural) - Programa de PósGraduação em Desenvolvimento Rural, UFRGS, Porto Alegre.

DESLANDES, Suely Ferreira. 2007. O projeto de pesquisa como exercício científico e artesanato intelectual. In: DESLANDES, Suely Ferreira; MINAYO, Cecília de Souza. Pesquisa Social: teoria, método e criatividade. Petrópolis: Vozes, p. 31.60.

FUNDAÇÃO DE ECONOMIA E ESTATÍSTICA. FEEdados. 2016. Disponível em: <http://feedados.fee.tche.br/feedados/>. Acesso em: 18 jun. 2016.

FLORES, Hilda Agnes Hübner. 2013. Mulheres na Guerra dos Farrapos. Porto Alegre: Martins Livreiro, 2013.

GUIZZO, Bianca Salazar; KRZIMINSKI, Clarissa de Oliveira; OLIVEIRA, Dora Lúcia Correa de. 2003. O software QSR NVivo 2.0 na análise qualitativa de dados: ferramenta para a pesquisa em ciências humanas e da saúde. Revista Gaúcha de Enfermagem, v. 24, n. 1, p. 53-60, 2003.

HIRATA, Helena. 2010. Novas configurações da divisão sexual do trabalho. Revista Tecnologia e Sociedade, v. 6, n. 11, p. 1-7, set./dez.

HIRATA, Helena; KERGOAT, Danièle. 2007. Novas configurações da divisão sexual do trabalho. Cadernos de Pesquisa, v. 37, n. 132, p. 595-609, set./dez.

KERGOAT, Danièle. 2010. Dinâmica e consubstancialidade das relações sociais. Novos estudos CEBRAP, n. 86, p. 93-103, março.

1996. Relações sociais de sexo e divisão sexual do trabalho. In: LOPES, Marta Júlia Marques; MEYER, Dagmar Estermann; WALDOW, Vera Regina. (Orgs.). Gênero e Saúde. Porto Alegre: Artes Médicas, p. 19.27. 
INSTITUTO BRASILEIRO DE GEOGRAFIA E ESTATÍSTICA - IBGE. IBGE Cidades. 2016. Disponível em:<http://www.cidades.ibge.gov.br/xtras/perfil.php?lang=\&codmun=430690\&search=rio-grandedo-sul|encruzilhada-do-sul|infograficos:-informacoes-completas $>$. Acesso em: 18 jun. 2016.

LOPES, Marta Julia Marques. 1996. Divisão do trabalho e relações sociais de sexo: pensando a realidade das trabalhadoras de saúde. In: LOPES, Marta Júlia Marques; MEYER, Dagmar Estermann; WALDOW, Vera Regina.(Orgs). Gênero e Saúde. Porto Alegre: Artes Médicas.

LUNARDI, Raquel. 2012. Mudanças nas relações de trabalho e gênero no turismo rural. Tese (Doutorado em Desenvolvimento Rural) - Programa de Pós-Graduação em Desenvolvimento Rural, Faculdade de Ciências Econômicas da UFRGS, Porto Alegre.

MELO, Hildete Pereira de; DI SABBATO, Alberto. 2009. Gênero e trabalho rural - 1993/2006. In: DI SABBATO, Alberto. Estatísticas rurais e a economia feminista: um olhar sobre o trabalho das mulheres. Brasília: MDA, p. 31.120.

MINAYO, Cecília de Souza. 2007. O desafio da pesquisa social. In: DESLANDES, Suely Ferreira; MINAYO, Cecília de Souza (Orgs.) Pesquisa Social: teoria, método e criatividade. Petrópolis: Vozes, p. 9-29.

PAULILO, Maria Ignez Silveira. 2004. Trabalho familiar: uma categoria esquecida de análise. Estudos Feministas, v. 12, n. 1, p. 229-252, jan./abril.

RAUBER, Cassiane da Costa. 2010. Masculinização da população rural no Rio Grande do Sul: análise a partir dos sistemas agrários. Dissertação (Mestrado em Extensão Rural) - Programa de Pós-Graduação em Extensão Rural, Centro de Ciências Rurais da UFSM, Santa Maria.

RIBAS, Rafael Perez; SEVERO, Christiane Marques; MIGUEL, Lovois de Andrade. 2004. "Evolução e Diferenciação dos Sistemas Agrários em Encruzilhada do Sul-RS: o contraste entre pequenos e grandes produtores rurais na ocupação de um mesmo espaço". In: XLII CONGRESSO SOBER, 42., 2004, Cuiabá. Anais... Cuiabá: Sociedade Brasileira de Economia, Administração e Sociologia Rural, p. 1-20.

RIBEIRO, Claudio Marques. 2009. Estudo do modo de vida dos pecuaristas familiares da Região da Campanha do Rio Grande do Sul. Tese (Doutorado em Desenvolvimento Rural) - Programa de Pós-Graduação em Desenvolvimento Rural, Faculdade de Ciências Econômicas da UFRGS, Porto Alegre.

SCOTT, Joan Wallach. 1995. “Gênero: uma categoria útil de análise histórica”. Educação \& Realidade, v. 20, n. 2, p. 71-99, jul./dez.

SCOTT, Parry. 2010. Gênero e geração em contextos rurais: algumas considerações. In: SCOTT, Parry; CORDEIRO, Rosineide; MENEZES, Marilda. (Orgs.). Gênero e Geração em contextos rurais. Florianópolis: Mulheres.

SOUZA, Rubia Elza Martins de; SILVA, Maria das Graças Silva Nascimento. 2012. "Mulher: a quebra do paradigma da função reprodutiva". Revista Geografares, v. n. 10, p. 203-224, mar.

STADUTO, Jefferson Andronio Ramundo; NASCIMENTO, Carlos Alves; SOUZA, Marcelino de. 2013 "Ocupações e renda das mulheres e homens no rural no estado do Paraná, Brasil: uma perspectiva de gênero". Cuadernos de Desarallo Rural, v. 10, n. 72, p. 91-115, jul./dez. 
TEDESCHI, Losandro Antônio. 2004. "Meu nome é 'ajuda': a vida cotidiana e as relações de poder, gênero e trabalho das mulheres trabalhadoras rurais na região Noroeste do Rio Grande do Sul”. Contexto e Educação, v. 19, n. 71/72, p. 45-64, jan./dez.

. 2012. "Mulheres e a sociedade agrária: representações sociais e relações de gênero". $\overline{S A E C U L U M ~-~ R e v i s t a ~ d e ~ H i s t o ́ r i a, ~ n . ~ 26, ~ p . ~ 295-310, ~ j a n . / j u n . ~}$

WANDERLEY, Maria de Nazareth. 2009. O Mundo rural como um espaço de vida: reflexões sobre a propriedade da terra, agricultura familiar e ruralidade. Porto Alegre: Ed. da UFRGS. 